\title{
The Effect of Defect Distribution on the Optical Storage Properties of Strontium Gallates with a Low Dimensional Chain Structure
}

Ting Wang ${ }^{\mathrm{a}}$, Xuhui Xu*a,b, Dacheng Zhou ${ }^{\mathrm{a}, \mathrm{b}}$, Yong Yang ${ }^{\mathrm{a}, \mathrm{b}},{ }_{\text {Jianbei Qiu }}^{\mathrm{a}, \mathrm{b}}$, Xue Yu*a,b

${ }^{a}$ School of Materials Science and Engineering, Kunming University of Science and Technology, Xuefu RD, Kunming 650093, PR China

${ }^{b}$ Key Laboratory of Advanced of Materials Yunnan Province, Kunming 650093, PR China

*E-mail address:xuxuh07@126.com; yuyu6593@126.com

*Tel: 86-0871-65188856. Fax: 86-0871-65188856 
Figure S1

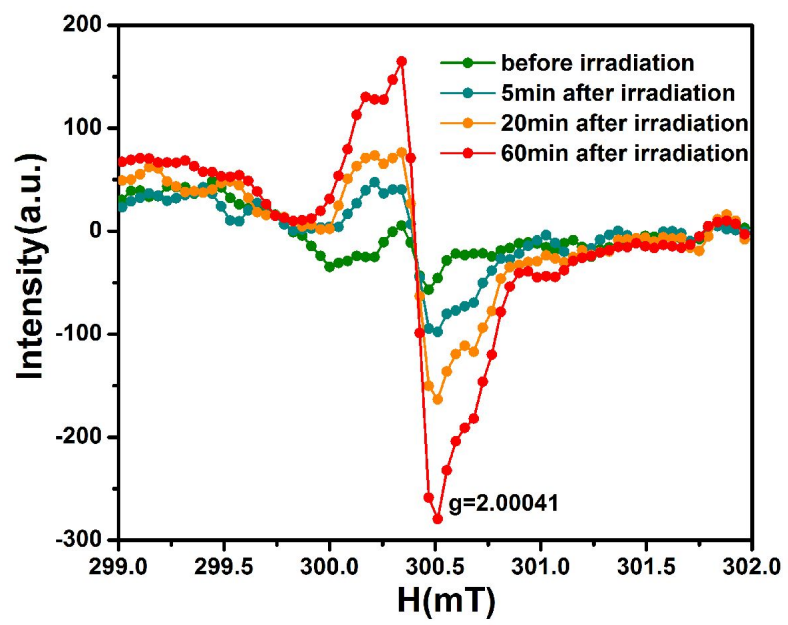

Figure S1 Electron spin resonance spectra of $\mathrm{SrGa}_{2} \mathrm{O}_{4}$ host measured at $100 \mathrm{~K}$, before irradiation, and after the stoppage of irradiation (5, 20, $60 \mathrm{~min})$.

Figure S2

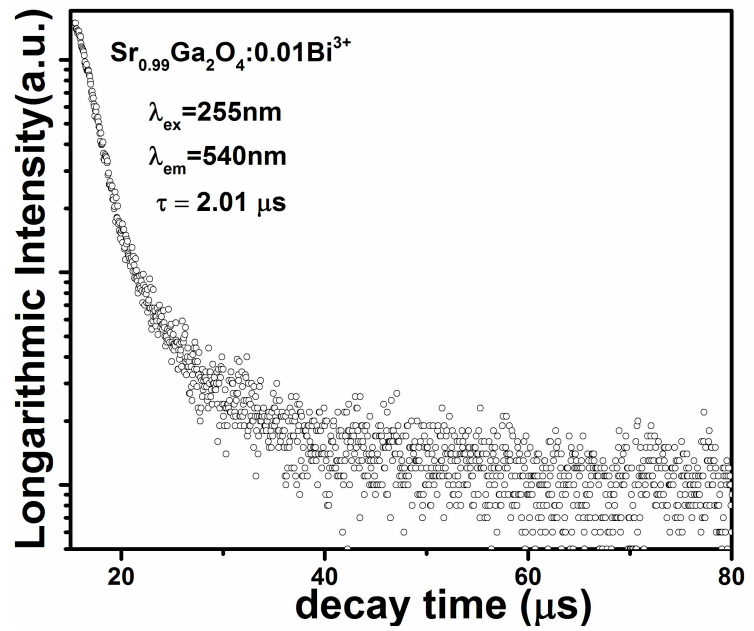

Figure S2 Fluorescence decay curves of $\mathrm{Sr}_{0.99} \mathrm{Ga}_{2} \mathrm{O}_{4}: 0.01 \mathrm{Bi}^{3+}(\lambda \mathrm{em}=540 \mathrm{~nm}, \lambda \mathrm{ex}=255 \mathrm{~nm})$. 
Figure S3

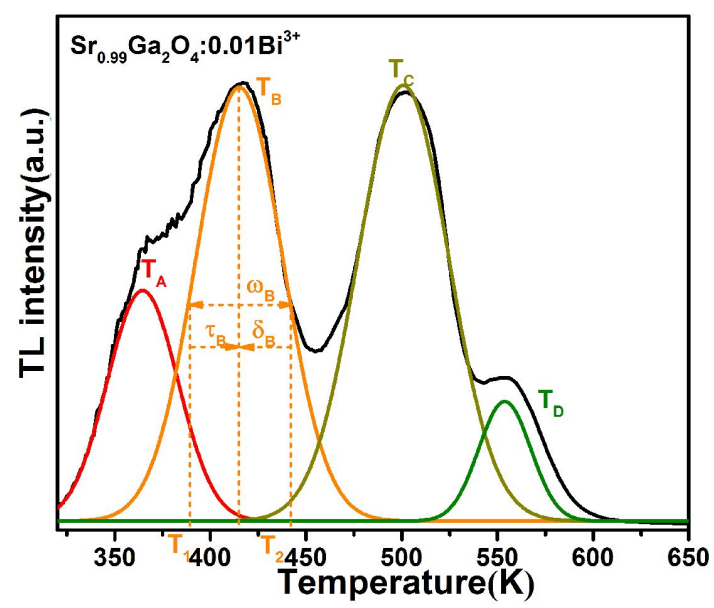

Figure S3 TL and fitting curves of $\mathrm{Sr}_{0.99} \mathrm{Ga}_{2} \mathrm{O}_{4}: 0.01 \mathrm{Bi}^{3+}$ phosphor.

Table S1 The parameters of the TL curves of $\mathrm{Sr}_{0.99} \mathrm{Ga}_{2} \mathrm{O}_{4}: 0.01 \mathrm{Bi}^{3+}$

\begin{tabular}{lcccccccc}
\hline Trap & $\mathrm{T}_{1}(\mathrm{~K})$ & $\mathrm{T}_{\mathrm{m}}(\mathrm{K})$ & $\mathrm{T}_{2}(\mathrm{~K})$ & $\tau$ & $\delta$ & $\omega$ & $\mu_{\mathrm{g}}$ & $\mathrm{E}(\mathrm{eV})$ \\
$\mathrm{A}$ & 341 & 362 & 384 & 21 & 22 & 43 & 0.511 & 0.843 \\
$\mathrm{~B}$ & 389 & 414 & 442 & 25 & 28 & 53 & 0.530 & 0.943 \\
$\mathrm{C}$ & 475 & 501 & 529 & 26 & 28 & 54 & 0.518 & 1.331 \\
$\mathrm{D}$ & 526 & 553 & 574 & 27 & 21 & 48 & 0.437 & 1.382 \\
\hline
\end{tabular}

